\title{
A LUTA FEMINISTA NA/PELA LINGUAGEM: APONTAMENTOS PARA UMA TRADUÇÃO DE LIVES OF GIRLS AND WOMEN ${ }^{1}$
}

Beatriz Gregório dos Santos é graduanda em Letras pela Universidade Estadual de Campinas (Unicamp). E-mail: bgregorio6@gmail.com

Érica Lima é professora do programa de pós-graduação em Linguística Aplicada e da graduação em Letras da Unicamp. E-mail: ericalalima@gmail.com

\section{Resumo}

Este trabalho objetiva retomar o contexto e características das propostas canadenses feministas de tradução, elaboradas por Simon (1996), von Flotow (1997), entre outras. Em seguida, apresenta-se alguns aspectos do conto Lives of Girls and Women, de Alice Munro, também relacionados ao feminismo. Por fim, propõe-se um projeto de tradução feminista para o conto, discutindo o papel da tradução e o poder da linguagem para as mudanças sociais e políticas.

\section{Palavras-chave}

Alice Munro. Feminismo. Lives of Girls and Women. Tradução feminista.

\section{1) Introdução: a proposta canadense de tradução feminista}

Desde a publicação de A Vindication of the Rights of Woman (1792), de Mary Wollstonecraft, mas principalmente a partir dos protestos das sufragettes pelo sufrágio universal, até chegar ao século XX com o Segundo sexo, de Simone de Beauvoir, e a luta pelo direito a seus próprios corpos e identidades, o feminismo vem trabalhando incansavelmente a favor das mulheres nas mais diversas esferas de representação, sempre questionando a visão da experiência masculina como única e universal. Embora tenha surgido como ideologia política no século XIX, foi só na década de 1960 que o pensamento feminista adentrou o campo acadêmico, "impondo-se como uma tendência teórica inovadora e de forte potencial crítico e político" (HOLLANDA, 1994, p. 7). Desde então, tal ideologia tem influenciado a revisão crítica de diferentes disciplinas científicas e humanistas, questionando, como nos diz Castro (2017, p. 219), "seu caráter supostamente neutro e objetivo e revelando que atendiam [...] aos critérios patriarcais".

Os Estudos da Linguagem não poderiam deixar de ser um dos focos das lutas feministas, uma vez que a língua é o lugar onde os sujeitos e suas experiências se constituem. Como já nos ensinou Bakhtin (2014), toda alocução expressa uma postura: visto que é permeada por ideologia, a língua nunca é neutra, transparente, mas sempre opaca; ela é, portanto, um instrumento de poder. A partir desse entendimento,

\footnotetext{
${ }^{1} \mathrm{O}$ projeto de tradução apresentado neste artigo está sendo desenvolvido por Beatriz Gregório dos Santos, sob a orientação de Érica Lima, com o apoio do Programa Institucional de Bolsas de Iniciação Científica do CNPq, com término previsto para julho de 2018.
} 
feministas começaram a refletir sobre as relações de poder presentes na linguagem e o lugar subordinado que a mulher nela ocupa. Não se vendo representadas, elas passaram a problematizar e a reformular certas leituras há muito consolidadas.

Na literatura, essa problemática é bastante evidente, já que a representação feminina nessa arte - e em todas as outras, se falarmos francamente - quase sempre parte de um olhar muito masculino. Dentre as diversas formas de artes existentes, a literatura é a que tem maior adesão feminina. Mesmo assim, as histórias privilegiadas são as escritas por homens, que descrevem as mulheres e suas experiências a partir de suas perspectivas. Conforme explica Schwantes (2006),

toda representação passa por uma subjetividade: alguém que determina o que é essencial e deve ser preservado e o que é acessório e pode ser descartado. Em uma sociedade em que a experiência masculina é valorizada e a experiência feminina é trivializada, o traço essencial a qualquer representação vai se prender à experiência masculina. (SCHWANTES, 2006, p. 11)

Mas é nos Estudos da Tradução que a luta pela linguagem se mostra ainda mais explícita, principalmente a partir da publicação de Gênero e a metafórica da tradução, de Lori Chamberlain, em 1988. Neste artigo, a autora discute como historicamente a tradução tem sido comparada à mulher. Isso porque, explica Chamberlain,

como mostra a pesquisa feminista, em diversas áreas, a oposição entre trabalho produtivo e reprodutivo determina o modo como os valores de uma cultura atuam: esse paradigma descreve originalidade e criatividade em termos de paternidade e autoridade, relegando à figura feminina uma série de papéis secundários. (CHAMBERLAIN, 2005, p. 38)

Assim, enquanto o escrever seria algo original e "masculino", o traduzir remeteria ao derivado e "feminino". Portanto, no original residiria "o que é natural, verdadeiro e legítimo; na cópia, o que é artificial, falso e traidor" (CHAMBERLAIN, 2005, p. 38). Para ilustrar essa comparação, Chamberlain (2005) apresenta algumas metáforas amplamente utilizadas no mundo da tradução. Dessas, a noção de les belles infidèles é o exemplo mais conhecido: cunhada no século XVII, a metáfora expõe muito bem a sexualização da tradução, captando "uma cumplicidade cultural entre as questões de fidelidade na tradução e no casamento" (CHAMBERLAIN, 2005, p. 39). O termo evoca a ideia de que as traduções seriam, assim como as mulheres, ou belas ou fiéis. E, tal como ocorre entre homem e mulher, a relação entre a tradução e o original possui um “contrato implícito", no qual “a esposa/tradução 'infiel' é publicamente julgada por 
crimes que o marido/original por lei é isento de cometer" (CHAMBERLAIN, 2005, p. 39).

De modo geral, os estudos de Chamberlain sobre as metáforas da tradução exploraram a reivindicação do tradutor ao seu direito à paternidade, exigindo que seu texto seja considerado legítimo, pois, em sua visão, seu trabalho é "uma atividade criativa", uma vez que "traduzir é como escrever" (CHAMBERLAIN, 2005, p. 51). A autora também enfatizou em seu texto "os mitos da paternidade (ou autoria e autoridade)" e a "ambivalência sobre o papel da maternidade" (CHAMBERLAIN, 2005, p. 45). Além disso, um dos pontos centrais para Chamberlain é salientar a associação entre tradução e mulher no discurso sobre o traduzir: à mulher coube a função de reproduzir a obra literária, encarregando-se sempre de uma tarefa dita secundária, enquanto o homem detinha o direito de produzir tais obras. Foi inclusive através da prática de traduzir que as mulheres adentraram o mundo da intelectualidade. Isso se deu porque, segundo Simon (1996), às mulheres foram negados os privilégios de autoria. A prática tradutória seria, portanto, a única forma possível de se expressarem pública e criativamente. Aqui, fica clara a distinção de valor entre o trabalho produtivo (a autoria, feita pelo homem) e o trabalho reprodutivo (a tradução, realizada pela mulher). Não há nada intrínseco à tradução que a caracterize como uma atividade essencialmente feminina, mas, como diz Chamberlain (2005),

embora obviamente tanto homens e mulheres façam traduções, a lógica binária que nos encoraja a definir o profissional de enfermagem como feminino e o de medicina como masculino, o de ensino como feminino e o de ensino superior como masculino, o de secretária como feminino e o de altos executivos como masculino, também mostra a tradução, de várias maneiras, como uma atividade de arquétipo feminino. (CHAMBERLAIN, 2005, p. 52)

A discussão de Chamberlain influenciou fortemente a junção de duas áreas de pesquisa distintas - os Estudos da Tradução e o feminismo -, mostrando que ambas têm diversos aspectos em comum: além de serem dotadas de um caráter interdisciplinar, tanto os Estudos da Tradução quanto o feminismo lidam com questões vistas como secundárias, derivadas, de "pouca importância".

$\mathrm{Na}$ década de 1980, percebendo interesses convergentes, as disciplinas se encontram e estudiosas das áreas começam a pensar uma teoria de tradução feminista, isto é, uma teoria que leve em consideração as relações de poder presentes na linguagem e o lugar subordinado que a mulher nela ocupa. Os dizeres de Lori Chamberlain ainda ecoam nos trabalhos das principais teóricas da área, como Barbara Godard (1990), 
Sherry Simon (1996) e Luise von Flotow (1997), mas também podemos atribuir o início da reflexão sobre uma tradução feminista aos textos experimentais de escritoras quebequenses na década de 1970 - como Nicole Brossard -, conhecidas por subverter a linguagem de modo a destacar a presença da mulher. Muitas das teóricas que hoje escrevem sobre a tradução feminista traduziram essas obras e, a partir delas, começaram a refletir sobre a posição da mulher na linguagem dos textos que traduziam e a questionar suas práticas.

A partir dessa reflexão, ficou claro que a língua pode ser um local de subordinação da mulher pelo homem - para von Flotow, a língua é a própria causa da opressão das mulheres, "o meio pelo qual as mulheres foram ensinadas e passaram a ter conhecimento de seu lugar subordinado no mundo" ${ }^{2 \prime}$ (VON FLOTOW, 1997, p. 8). A tradução então foi apropriada como um dos diversos elementos da luta feminista, a fim de empoderar, representar e destacar a mulher na linguagem. E, "no momento em que a mulher não aceita a posição secundária da tradução, ela protesta também contra a posição secundária da mulher em relação ao homem" (DÉPÊCHE, 2005³ apud CASTRO, 2007, p. 66). Assim, à mulher tradutora é dada a possibilidade de romper com o silêncio imposto e de transmitir as experiências femininas e sua relação com a linguagem. Traduzindo, a tradutora afirma sua diferença crítica e produz um novo discurso, um novo enunciado que se sobrepõe ao discurso dominante que a oprime. A tradução seria, portanto, um meio de criação de novos significados e de novas possibilidades de intepretação. Mas, como bem explica Simon (1996),

[o]s meios que as tradutoras usam para chamar a atenção para as suas identidades como mulheres - ou mais especificamente como feministas - são destacados aqui para explicar as afinidades ou frustrações que sentem em seu trabalho de tradução e para esclarecer os textos que de fato exploram os recursos dos gêneros gramaticais para fins imaginativos ou políticos. Gênero nem sempre é um fator relevante na tradução. Não há características a priori que tornem as mulheres mais ou menos competentes em suas tarefas. Onde a identidade entra em jogo é o ponto em que a tradutora transforma o gênero em um projeto social ou literário (SIMON, 1996, p. 7) ${ }^{4}$.

\footnotetext{
2 "the medium through which women were taught and came to know their subordinate place in the world" (VON FLOTOW, 1997, p. 8). Essa e todas as demais traduções de obras não traduzidas para o português são nossas.

${ }^{3}$ DÉPÊCHE, Marie-France. A tradução como ato político. In: SWAIN, Tânia; MUNIZ, Diva (orgs.) Mulheres em Ação: Práticas discursivas, práticas políticas. Florianópolis: PUC Minas Editora, 2005, pp. 269-303.

4 "The ways in which translators draw attention to their identities as women - or more specifically as feminists - are highlighted here in order to explain the affinities or frustrations they feel in their translation work, and in order to elucidate texts which themselves exploit the resources of grammatical gender for imaginative or political purposes. Gender is not always a relevant factor in translation. There
} 
Termos como "subversão", "intervenção" e "manipulação" são frequentes na teorização desse discurso, assim como nas notas explicativas e prefácios dos livros traduzidos que, como explica Godard (1990), são recursos muito utilizados pelas tradutoras feministas para exibir sua assinatura e ostentar os sinais de sua manipulação. Essas tradutoras não têm a pretensão de serem "invisíveis". Da mesma forma, seu compromisso não é manter-se fiel ao texto de origem, mas sim manipular a linguagem para que fale em favor das mulheres e vá contra a ordem falocêntrica dominante (CASTRO, 2007). E só a infidelidade permite que sua agenda política vá adiante. A tradução feminista é uma operação criativa, não mera recriação; ela é uma prática altamente transformadora e de caráter político muito evidente.

Para Paulo Henriques Britto (2016), porém, propostas de tradução tais como a feminista não são "éticas", visto que suas tradutoras são deliberadamente infiéis ao texto-fonte. Britto defende que

o tradutor tem a obrigação de se esforçar ao máximo para aproximarse tanto quanto possível da inatingível meta de fidelidade, e que ele não tem o direito de desviar-se desse caminho por outros motivos. [...] $\mathrm{O}$ tradutor que coloca no texto anacronismos propositais para que o leitor se lembre de que está lendo uma tradução, ou que altera uma passagem de modo consciente para enunciar uma posição ideológica do autor, está, no meu entender, agindo de maneira antiética, na medida em que deveria estar atuando na qualidade de tradutor. Ele tem todo o direito de se tornar visível, mas as maneiras apropriadas de fazê-lo são outras [...] ele não tem o direito de se tornar visível intervindo de modo ostensivo no texto do autor, para chamar a atenção do leitor que o que ele está lendo é uma tradução; ao agir assim, ele está violando o seu compromisso básico, que é o de se esforçar ao máximo para que, após ter lido sua tradução, o leitor possa afirmar, sem mentir, que leu o original" (BRITTO, 2016, p. 38, grifos nossos).

A recusa pela invisibilidade se dá porque essas tradutoras feministas sabem que elas (e todos/as tradutores/as, independentemente da ideologia que seguem) fazem um trabalho importantíssimo, que estão envolvidas nas políticas de transmissão e que ajudam na perpetuação e na contestação dos valores da cultura. Então, na visão de Godard (1990), von Flotow $(1991$; 1997) e de tantas outras feministas que se dedicam à tarefa de traduzir, a tradução feminista é uma prática fundamental. Por isso, ainda que seja extremamente necessário traduzir textos de mulheres (feministas ou não), para desse modo "compactuar de um mercado em expansão, um nicho que precisa ganhar

are no a priori characteristics which would make women either more or less competent at their task. Where identity enters into play is the point at which the translator transforms the fact of gender into a social or literary project" (SIMON, 1996, p. 7). 
mais visibilidade" (SCHAFFER, 2010, p. 280), obras clássicas, escritas por homens e lidas tradicionalmente a partir de um olhar masculino, podem (e devem!) ganhar traduções feministas, pois, de acordo com Maria Tymoczko (2013),

a ideologia de uma tradução não reside simplesmente no texto traduzido, mas no modo de expressão e na postura do(a) tradutor(a), bem como na relevância dessa tradução para seu público. Esses últimos aspectos são influenciados pelo lugar de enunciação do tradutor [...] Tais aspectos da tradução são motivados e determinados pelas afiliações culturais e ideológicas do(a) tradutor(a), assim como ou ainda mais motivados pela localização espacial e temporal de onde ele (ela) fala (TYMOCZKO, 2013, p. 118).

Lidas a partir de outro olhar, essas novas traduções podem "refletir e chamar a atenção aos aspectos do texto fonte que são novos, ou inovadores, ou considerados ‘úteis' para o novo público leitor" (VON FLOTOW, 2013, p. 180). É o caso, por exemplo, de The Woman's Bible (1895) e da versão francesa da Bíblia publicada em 2001, que trouxeram à tona detalhes do texto bíblico - principalmente em relação às mulheres - que foram apagados ou transformados em suas traduções anteriores. Também é o caso da nova tradução para o inglês da Odisseia, feita pela primeira vez por uma mulher - Emily Wilson: agora temos um olhar feminino sobre o grande épico de Homero, um olhar que se sensibiliza com as questões das mulheres e procura soluções para sua tradução que não as depreciem, como fizeram alguns tradutores que levaram a Odisseia para a língua inglesa.

Essas novas traduções, feitas por sujeitos que partem de um outro lugar - e sabemos que é a "posição a partir da qual o sujeito fala que determina seu dizer" (SCHAFFER, 2010, p. 271) - possibilitam novas leituras e interpretações de textos tão consagrados. E von Flotow (2013) acrescenta:

ao longo das centenas de séculos de adaptação e tradução em culturas patriarcais agressivas, esses detalhes foram desaparecidos, escondidos e perdidos, de forma que sistemas sociais e políticos inteiros puderam ser fundados na natureza 'secundária' das mulheres, vindas em segundo lugar na Criação, derivadas do corpo de Adão [...] (VON FLOTOW, 2013, p. 173).

Um bom exemplo do que estamos discutindo aqui nos é apresentado por von Flotow (1997), que relata o caso de Susanne de Lotbinière-Harwood, feminista e tradutora canadense. Bastante experiente na área, Lotbinière-Harwood era conhecida principalmente por traduzir para o inglês os poemas do músico e poeta Lucien Francouer (ela inclusive chegou a ser premiada pela tradução de uma de suas obras). Porém, depois de receber elogios dizendo que sua tradução era ainda melhor que o 
próprio poema original, Lotbinière-Harwood começou a refletir sobre sua prática. A feminista então se deu conta que suas traduções partiam de uma perspectiva masculina, como se fosse um homem olhando para uma mulher e, ao constatar isso, decidiu nunca mais traduzir obras literárias escritas por homens.

A partir de então, a luta de Lotbinière-Harwood através da linguagem se deu não só pela sua decisão de não traduzir homens, mas também porque escolheu feminizar suas traduções. Segundo Castro, "quando são escritas em francês, de forma neutra ou 'genérica' (ou seja, no gênero masculino, assim como no português), ela faz questão de traduzir para o inglês, transformando tudo em feminino" (CASTRO, 2007, p. 62). Além disso, a tradutora entende que tem o direito de mudar aspectos do texto-fonte em sua tradução se não concorda com que a autora diz. Para explicar sua posição e defender sua intervenção, Lotbinière-Harwood se utiliza de espaços privilegiados como o prefácio. Ao traduzir Lettres d'une autre, de Lise Gauvin (publicado originalmente em francês em 1984, lançado em tradução para o inglês em 1989), por exemplo, a tradutora escreve:

\begin{abstract}
Querido(a) leitor(a),
Apenas algumas palavras para que saiba que esta tradução é uma reescrita no feminino do que eu li originalmente em francês. Não falo de conteúdo. Lise Gauvin é feminista e eu também. Mas não sou ela. Ela escreveu no genérico masculino. Minha prática de tradução é uma atividade política que visa a fazer a língua falar pelas mulheres. Assim, minha assinatura em uma tradução significa: esta tradução usou toda estratégia possível de tradução feminista para tornar o feminino visível na linguagem. Isso significa fazer com que as mulheres sejam vistas e ouvidas no mundo real. E esse é objetivo do feminismo ${ }^{5}$ (LOTBINIÈRE-HARWOOD, $1989^{6}$, p. 9 apud VON FLOTOW, 1997, p. 29).
\end{abstract}

Não só ela, mas diversas tradutoras inseridas no mesmo contexto que LotbinièreHarwood começaram a refletir sobre "por que estavam trabalhando em textos que, de repente, pareciam estranhos a elas, textos de cujas premissas elas não

\footnotetext{
5 "Dear reader, just a few words to let you know that this translation is a rewriting in the feminine of what I originally read in French. I don't mean content. Lise Gauvin is a feminist, and so am I. But I am not her. She wrote in the generic masculine. My translation practice is a political activity aimed at making language speak for women. So my signature on a translation means: this translation has used every possible feminist translation strategy to make the feminine visible in language. Because making the feminine visible in language means making women seen and heard in the real world. Which is what feminism is all about" (LOTBINIÈRE-HARWOOD, 1989, p. 9 apud VON FLOTOW, 1997, p. 29).

${ }^{6}$ LOTBINIÈRE-HARWOOD, Suzanne de. "About the her in other". In: GAUVIN, Lise. Letters from an Other. Toronto: The Women's Press, 1989.
} 
compartilhavam", ao mesmo tempo em que "estavam descobrindo uma escrita feminista com a qual sentiam enorme afinidade" ${ }^{8,}$ (SIMON, 1996, p. 8).

Para compreender o encontro da tradução com o feminismo é necessário que se reflita sobre a posição subalterna que a mulher ocupa em nossa sociedade, o status marginal atribuído à tradução e também suas transformações a partir das contribuições de outras áreas na teoria tradutória. Como bem sintetiza von Flotow (1997, p. 76), "as visões históricas sobre as mulheres e os controles políticos impostos a elas encontram um bom paralelo na posição também 'degradada' da tradução"”. Os Estudos da Tradução e os Estudos de Gênero acrescentaram (e ainda têm muito a acrescentar) um ao outro. Nesse sentido, ainda se fazem necessários mais sobre tradução e gênero, principalmente porque a intersecção entre essas duas áreas de pesquisas continua sendo um lugar que mostra que a tradução inevitavelmente traz consigo elementos ideológicos, culturais e políticos.

\section{2) Lives of Girls and Women, de Alice Munro}

Publicado em 1971, Lives of Girls and Women é a segunda obra da célebre escritora canadense Alice Munro. Por muitas vezes classificado como um romance, o livro é uma coleção de contos independentes que são interligados por possuírem a mesma protagonista, Del Jordan, jovem moradora da pequena cidade de Jubilee, zona rural da província canadense de Ontário. Nesses contos, nós acompanhamos, a partir de uma narração em primeira pessoa, a vida e o processo de formação da subjetividade de Del que, em um rememorar de sua história, explora as contradições do que é ser mulher a partir de relatos de suas experiências com o sexo, o nascimento e a morte.

Ainda que inconscientemente, Del é bastante influenciada pelas figuras femininas que vivem ao seu redor, embora rejeite ter o mesmo destino que elas: todas são mulheres aprisionadas em um ambiente rural, aparentemente sem grandes sonhos ou ambições, contentando-se em repetir o que se espera delas. Em suas narrativas, Del nos apresenta questionamentos em torno da busca pela construção de uma identidade própria, numa tentativa de encaixar-se no mundo onde vive, em que os exemplos que vê não correspondem ao que ela deseja ser.

\footnotetext{
7 "why they were working on texts which suddenly seemed alien to them, texts whose premises they could not share" (SIMON, 1996, p. 8).

${ }^{8}$ women were discovering feminist writing with which they felt intense affinities" (SIMON, 1996, p. 8).

${ }^{9}$ Historical views of women and the political controls imposed upon them thus find an easy parallel in the similarly "degraded" position of translation" (VON FLOTOW, 1997, p. 76).
} 
Em toda a sua obra, Alice Munro aborda o cotidiano de mulheres simples de pequenas cidades do Canadá, geralmente com situações e imagens entre membros da mesma família, tudo com bastante clareza e realismo psicológico. A autora, porém, faz isso de maneira bastante inusitada, recorrendo sempre a elementos inesperados, levando o enredo a uma mudança completa de rumo. Como bem resume Gonçalves (2013), Munro

utiliza-se de uma estrutura fragmentada, marcada por mudanças inesperadas de tempo e espaço físico, pela polifonia de vozes, pela pluralidade de visões e versões e pelo contraste de gerações. Ademais, suas narrativas destacam-se pelo emprego recorrente de protagonistas femininas, pelos desfechos inconclusos e finais em aberto e pelo trabalho com a memória (GONÇALVES, 2013, p. 22).

Munro é autora exclusivamente de contos, e foi escrevendo narrativas curtas que estabeleceu uma sólida carreira literária. A contista foi tão bem-sucedida nessa empreitada que hoje carrega o título de "mestre do conto contemporâneo", isso porque em poucas páginas ela consegue criar histórias sensíveis, sempre de forma simples, mas com uma escrita arguta, bastante subjetiva, recheada de "fatos corriqueiros transformados em visões epifânicas” (BRASIL, 2016).

Por todas essas razões, achamos interessante propor uma tradução feminista para o conto Lives of Girls and Women (inédito em português), de Alice Munro. Esse é um conto lido como feminista, mas que não explicita a mulher na linguagem da forma como as teóricas da tradução feministas defendem. Principalmente - mas não unicamente porque Munro escreveu seu conto em inglês, uma língua cheia de palavras neutras e epicenas, diferentemente do português, língua com gênero gramatical, que explicita constantemente o sexo das e dos referentes.

Foram traçadas algumas diretrizes para o projeto de tradução, ainda em fase inicial, que buscam contemplar a concepção feminista de tradução, principalmente em relação à visibilidade do feminino e ao emprego de uma terminologia mais neutra em casos em que, em inglês, não é evidenciado o gênero daquela/e a quem se refere. Adotase, então, a tradução para substantivos sobrecomuns, epicenos ou comum de dois gêneros. Entretanto, apenas tal opção não basta: há casos em que cabem soluções explicitamente feministas. Podemos citar o momento em que Ada, mãe de Del, protagonista e narradora da história, defende o caráter de Fern Dogherty, sua amiga, dizendo que "If Fern Dogherty was not a good woman [....] do you think I would have her living in my house?" (MUNRO, 2001, p. 162, grifo nosso). A proposta mais feminista não traria "se Fern Dogherty não fosse uma boa mulher [...]", mas 
transformaria tal frase em "Se Fern Dogherty fosse uma vadia [...] você acha que eu iria querê-la na minha casa?”.

Essa estratégia de chocar o leitor com uma palavra que seria facilmente usada por aqueles que têm uma representação da mulher como aquela que possui modos de vida amorais, deixa de lado o eufemismo do "boa mulher" que, no diálogo, dificilmente estaria se referindo a alguém generoso, caridoso ou com aptidão profissional, ou seja, sentidos possíveis, mas pouco prováveis, para o termo "good" no contexto em questão. Essa estratégia pode ser encontrada no texto "Feminist translation: contexts, practices and theories", de von Flotow (1991, p. 69), artigo em que a autora apresenta o caso em que uma tradutora feminista, ao traduzir a frase "Ce soir $\mathrm{j}$ 'entre dans l'histoire sans relever ma jupe", optou por, em vez de traduzi-la de modo mais tradicional ("this evening I'm entering history without pulling up my skirt"), traduzir tal frase para o inglês como "this evening I'm entering history without opening my legs"10 - uma tradução muito mais chocante, que explicita o que está implícito no texto. O mesmo efeito pode surgir com essa opção de tradução do texto de Munro, já que Fern Dogherty é vista com maus olhos pela população da cidade onde vive.

Outro exemplo é a frase "she was dropping ashes on her stomach, which, ungirdled, popped out in a pregnant curve" (MUNRO, 2001, p. 160, grifo nosso), em que poderíamos ter, no lugar de "grávida", o termo "prenhe". Dessa forma, teríamos os dois significados trazidos pelos dicionários ${ }^{11}$, ou seja, "pregnant" como "woman or female animal having a child or young developing in the uterus" e também como algo "full of meaning; significant or suggestive". Além disso, em português, o termo "grávida" geralmente refere-se a mulheres (e não a animais), já o termo "prenhe ${ }^{12 "}$ é mais comum para designar a gravidez de animais e, quando usado para mulheres, costuma desencadear outros sentidos. A ideia de "cheio", "repleto", "pleno" aparece em "prenhe", porém dificilmente ocorre na palavra "grávida". Teríamos, então, "ela estava derrubando cinzas em seu estômago, que, desajeitado, pareceu prenhe”.

\footnotetext{
10 "Esta noite, estou entrando para a história sem levantar a minha saia", no primeiro caso, e "esta noite, estou entranto para a história sem abrir as minhas pernas", no segundo.

11 Por exemplo: "definition of pregnant in English", Oxford Living Dictionaries. Disponível em: <https://en.oxforddictionaries.com/definition/pregnant〉. Acesso em: 25 jan. 2018.

12 1. Diz-se de fêmea no período de gestação; 2. Fig. Cheio, pleno, repleto: prenhe de sabedoria: "E grato refrigério vens trazer-lhe/ No teu remansear prenhe de enlevos!" (Gonçalves Dias, A tarde.). Disponível em: http://www.aulete.com.br/prenhe. Acesso em: 13 abr. 2018.
} 
Uma versão feminista também poderia ser adotada quando, ao relembrar um relato do sr. Chamberlain sobre venda de meninas menores de idade como escravas sexuais na Itália, Del, divagando, diz "a man paid you to let him do it. What did he say? Did he take your clothes off or did he expect you to do that yourself? Did he take down his pants or did he simply unzip himself and point his thing at you? (MUNRO, 2001, p. 168, grifos nossos). Ainda que Munro esteja abordando um assunto extremamente violento, ela usa palavras mais "suaves" para referir-se ao problema. Em uma tradução feminista, porém, explicitar a violência aqui retratada é essencial, por isso optamos por traduzir tal passagem para "um homem pagou você para que pudesse estuprá-la. O que ele disse? Ele arrancou suas roupas ou esperou que você mesma fizesse isso? Ele abaixou as calças ou simplesmente abaixou o zíper e enfiou o pinto em você?”. Todas essas escolhas são mais chocantes do que "um homem pagou você para que pudesse fazer aquilo. O que ele disse? Ele tirou suas roupas ou ele esperou que você mesma fizesse isso? Ele abaixou as calças ou simplesmente abaixou o zíper e mostrou a coisa dele para você?"

Outro momento em que uma tradução feminista poderia ser adotada surge quando, em uma conversa com o sr. Chamberlain, Del narra que "he looked at me in mocking surprise as he always did when I said anything" (MUNRO, 2001, p. 165, grifos nossos). Em nossa tradução, essa frase ficou: "ele me olhou com uma cara de deboche, como ele sempre faz quando digo alguma coisa". Ainda no mesmo contexto, Munro escreve: "Things like that happen in a war", said my father quietly but with some severity, as if to object to any of this showed a certain female naiveté" (MUNRO, 2001, p. 165, grifos nossos). Em português, decidimos traduzir "female naiveté" como "burrice feminina". Nossa tradução, então, foi: "Coisas como essa acontecem numa guerra", disse meu pai calmamente, mas com alguma seriedade, como se ser contra aquelas coisas mostrasse uma certa burrice feminina". Ainda que nem "female naiveté" nem "mocking surprise" tenham sentidos tão pejorativos quanto "burrice" e "deboche", escolhemos assim traduzir tais palavras para evidenciar no texto de Alice Munro o senso comum de que, na perspectiva masculina, aquilo que a mulher pensa ou fala geralmente é bobagem ou está incorreto.

Dessa forma, uma tradução feminista de Lives of Girls and Women pode ajudar na construção das personagens, enfatizando a resistência aos modelos tradicionais de comportamento e representações que uma cultura masculina tem das mulheres. Assim, ao mesmo tempo em que as mulheres e a protagonista são apresentadas como 
subjugadas pelos homens, também resistem à repressão, procurando um espaço próprio. Ao trazer para o conto questões relacionadas à sexualidade da mulher, à violência (traições, estupros, assaltos) e à subjetividade feminina, o conto possibilita leituras que refletem o momento histórico em que foi publicado e uma proposta de tradução feminista se coaduna com tal período.

\section{3) Considerações finais}

Atualmente, várias abordagens trazem, para a esfera dos Estudos da Tradução, questões relativas ao papel político e ideológico do tradutor, como é o caso da tradução feminista. Embora o apogeu das pesquisas e publicações da área tenha ocorrido entre o final do século XX e início deste, há ainda muitos estudos a serem feitos para que os discursos falocêntricos tradicionais deem lugar à equidade entre homens e mulheres. Não se trata de substituir o "manhandling" por "womanhandling", mas de pensar fora das clássicas dicotomias que sempre nos acompanharam.

A linguagem tem um papel primordial para refletirmos como a mulher e o feminino são vistos na nossa sociedade atual. Alguns passos já foram dados, e outros estão se concretizando aos poucos, como pode ser visto com o uso de "marcas" que são diferentes em cada língua, cultura e país. Se, de um lado, há uma maior visibilidade, por meio de @, x ou "e" (como em amig@s, amigxs ou amigues), por outro, tais recursos dificultam a leitura e, pelo menos nos dois primeiros casos, podem ser vistos, mas não ouvidos, o que aponta para uma outra questão: a primazia do escrito sobre o falado, além de muitas vezes ainda não serem compreendidos.

A tradução tem uma função de mudança cultural, política e social, por isso é tão importante que haja uma conscientização do poder da linguagem. Desse modo, cabe à tradutora feminista assumir a responsabilidade por sua leitura e por seu posicionamento, porém, com tal postura, ela assume também o risco trazido por qualquer tradução ideologicamente ativista. Esse foi um dos pontos mais criticados da tradução feminista canadense: a manipulação e subordinação dos textos traduzidos a um propósito muitas

vezes bem distante daquele pretendido pelo texto de partida. É por isso que a seleção do texto a ser traduzido é primordial, já que as estratégias funcionarão melhor e terão melhores resultados naqueles textos mais marcados ideologicamente.

Há, inegavelmente, uma contribuição da tradução feminista para os Estudos da Tradução, especialmente em relação a questões sociais e de poder. Nesse sentido, a 
importância deste trabalho consiste em chamar a atenção para as estratégias feministas usadas, demonstrando que a opressão ainda é muito presente em algumas culturas.

Pode-se concluir que o feminismo que se pretende apresentar na tradução de Munro é só um dentre os vários feminismos hoje existentes. O contexto atual é diferente daquele em que as traduções canadenses foram concebidas. No entanto, as reivindicações femininas continuam necessárias, bem como o estudo das representações criadas nas diversas línguas - especialmente aqui, na língua portuguesa, caracterizada pela predominância da marca do masculino em detrimento do feminino e, poucas vezes, pelo uso de um léxico mais neutro. Dessa forma, não se trata apenas de usar estratégias feministas de linguagem, mas de torná-las conhecidas, estudando-as e divulgando-as, especialmente no contexto brasileiro, em que ainda são necessárias ações que fortaleçam ideias feministas, discussões a respeito de gênero e ações que mostrem, de forma mais ostensiva, que há muito o que se estudar e se dizer sobre o lugar da mulher na sociedade.

\section{Referências}

BAKHTIN, Mikhail. Marxismo e filosofia da linguagem: problemas fundamentais do método sociológico na ciência da linguagem. Tradução de Michel Lahud, Yara Frateschi Vieira. 16. ed. São Paulo: Hucitec, 2014.

BRASIL, Ubiratan. Contos de Alice Munro inspiram roteiro do filme 'Julieta', de Almodóvar. Estado de São Paulo, São Paulo: 07 de julho de 2016. Disponível em: $<$ http://cultura.estadao.com.br/noticias/cinema,contos-de-alice-munro-inspiram-roteirodo-filme-julieta-de-almodovar,10000061395>. Acesso em 06 de abr. de 2018.

BRITTO, Paulo Henriques. A tradução literária. 2 ed. Rio de Janeiro: Civilização Brasileira, 2016.

CASTRO, Marcelle de Souza. Tradução, ética e subversão: desafios práticos e teóricos. 2007. 116 f. Dissertação (Mestrado em Letras) - Pontifícia Universidade Católica do Rio de Janeiro, 2007.

CASTRO, Olga. (Re)examinando horizontes nos estudos feministas de tradução: em direção a uma terceira onda? Tradução de Beatriz Barboza. TradTerm, São Paulo, v. 29, p. 216-250, jul. 2017.

CHAMBERLAIN, Lori. Gênero e a metafórica da tradução. Trad. Norma Viscardi. In: OTTONI, Paulo (org.). Tradução: a prática da diferença. Campinas: Editora da Unicamp, 2005. p. 37-58.

GODARD, Barbara. Theorizing feminist discourse/translation. In: LEFEVERE, André; BASSNETT, Susan (org.). Translation, history and culture. New York: Pinter Publishers Limited, 1990. p. 87-96. 
GONÇALVES, Patricia Magazoni. Voz narrativa e memória: a busca de identidade pelas protagonistas de Felicidade Clandestina, de Clarice Lispector e de Lives of Girls and Women, de Alice Munro. 2013. 176 f. Dissertação (Mestrado em Letras) Faculdade de Ciências e Letras, Universidade Estadual Paulista "Júlio de Mesquita Filho", 2013.

HOLLANDA, Heloisa Buarque. Tendências e impasses: o feminismo como crítica da cultura. Rio de Janeiro: Rocco, 1994.

MUNRO, Alice. Lives of girls and women. Nova Iorque: Vintage Books, 2001.

SCHÄFFER, Ana Moura. A tradução de gênero entre fal(t)as e excessos no imaginário de tradutoras brasileiras. Sínteses, Campinas, v. 15, p. 266-287, 2010.

SCHWANTES, Cíntia. Dilemas da representação feminina. OPSIS, Goiania, v. 6, n. 1, p. 7-17, 2006.

SIMON, Sherry. Gender in translation: cultural identity and the politics of transmission. London; New York: Routledge, 1996.

TYMOCZKO, Maria. Ideologia e a posição do tradutor: em que sentido o tradutor se situa no 'entre'(lugar)?. Trad. Ana Carla Teles. In: BLUME, Rosvitha Friesen; PETERLE, Patricia (orgs.). Tradução e relações de poder. Tubarão: Ed. Copiart; Florianópolis: PGET/UFSC, 2013. p. 115-148.

VON FLOTOW, Luise. Feminist translation: contexts, practices and theories. TTR, vol.4, n. 2, p. 69-84, 1991.

VON FLOTOW, Luise. Translation and gender: translating in the "era of feminism". Manchester: St. Jerome Publishing, 1997.

VON FLOTOW, Luise. Traduzindo mulheres: de histórias e re-traduções recentes à tradução 'Queerizante' e outros novos desenvolvimentos significativos. Trad. Tatiana Nascimento dos Santos. In: BLUME, Rosvitha Friesen; PETERLE, Patricia (orgs.). Tradução e relações de poder. Tubarão: Ed. Copiart; Florianópolis: PGET/UFSC, 2013. p. 169-192.

\title{
THE FEMINIST STRUGGLE IN/FOR LANGUAGE: BRIEF NOTES FOR A TRANSLATION OF LIVES OF GIRLS AND WOMEN
}

\begin{abstract}
This paper summarizes the context and characteristics of the Canadian feminist proposals for translation developed by Simon (1996), von Flotow (1997), and others. Subsequently, some features of Alice Munro's short story Lives of Girls and Women, which also deal with feminist issues, are presented. Finally, a feminist translation project for the short story is proposed, discussing the role of translation and the power of language to bring about social and political change.
\end{abstract}

\section{Keywords}

Alice Munro. Feminism. Lives of Girls and Women. Feminist Translation. 